\title{
Disease Resistance of Tissue-cultured Seedlings of Rhododendron after Treatment with Streptomyces sp. R-5
}

\author{
Masafumi SHIMIZU ${ }^{1}$, Norikazu FUJITA ${ }^{1}$, Yoshiko NAKAGAWA ${ }^{2}$, Tomio NISHIMURA ${ }^{2}$, \\ Tamotsu FURUMAI ${ }^{3}$, Yasuhiro IGARASHI ${ }^{3}$, Hiroyasu ONAKA ${ }^{3}$, Ryuji YOSHIDA ${ }^{4}$ and Hitoshi KUNOH ${ }^{*}$
}

\begin{abstract}
An endophytic actinomycete, Streptomyces sp. R-5, which had been isolated from a field-grown rhododendron plant, was used to protect rhododendron seedlings in tissue culture from Pestalotia disease caused by Pestalotiopsis sydowiana. R-5 had intense antagonistic activity against $P$. sydowiana without adversely affecting the seedlings in glass flasks. A suspension of R-5 was spread on the surface of the multiplication medium in glass flasks in which seedlings were growing. Ten days later, the 4th upper leaf of seedlings was inoculated with $P$. sydowiana and incubated for 14 days. In controls untreated with R-5, substrate mycelia of $P$. sydowiana grew on all leaves and stems above and below the 4th leaf within 2-3 days of inoculation. Such growth resulted in the wilting death of $54 \%$ of seedlings by 14 days. In contrast, only the inoculated leaves turned brown in $c a .90 \%$ of seedlings growing on medium treated with $R-5$. None of these seedlings died. Thus, treatment of the medium surface with R-5 efficiently protects the seedlings from infection by $P$. sydowiana. Scanning electron microscopy revealed that substrate mycelia of $R-5$ grew on and beneath the cuticle of leaves of the treated seedlings. Fluorescent microscopy showed that R-5 was also inside the leaves.
\end{abstract}

(Received June 8, 2001; Accepted July 4, 2001)

Key words : Endophytic Streptomyces sp., resistance, tissue-culture, rhododendron.

\section{INTRODUCTION}

Microbe-based biological control of plant diseases has increased in agricultural importance as replacements or supplements for agrochemicals, which may pollute the environment and affect nontarget organisms. The success of biocontrol largely depends on basic knowledge about the selected antagonist. Generally, biocontrol candidate of agents are selected using an in vitro test of their antagonistic activity against target pathogens. However, as Rukayadi et al. ${ }^{15)}$ emphasized, the subsequent in vitro experiments hold a key to the success of biocontrol, because the selected agent may lose its antagonism when environmental conditions change and the respective microbes may respond differently to these changes.

Plant-associated microbes sometimes give physiological and environmental advantages to their host plants. For example, Narisawa et al. ${ }^{8}$ reported that Chinese cabbage seedlings grown from seeds treated with endophytic Heteroconium chaetospira became resistant to Plasmodio- phora brassicae, and their growth was significantly promoted. Furthermore, Varma et al. ${ }^{23)}$ found that when calli of tobacco and seeds of maize, tobacco and parsley were treated with Piriformospora inidca, growth of shoots and roots of these plants was greatly promoted. van Wees et $a ._{.}^{22)}$ demonstrated that selected strains of nonpathogenic rhizobacteria from the genus Pseudomonas elicited broad-spectrum induced systemic resistance. In all these reports, endophytic microbes affected the physiology of their host plants.

We previously tested antifungal activity of 10 isolates of actinomycetes obtained from field-grown rhododendron $^{18)}$. An isolate of Streptomyces sp. R-5, which had the most intense antagonistic activity against Phytophthora cinnamomi and Pestalotiopsis sydowiana, major pathogens of rhododendron, was selected as a potential biocontrol agent. In this paper we describe the control of Pestalotia disease, caused by Pestalotiopsis sydowiana, on tissue-cultured rhododendron seedlings in glass flasks after treatment of the medium surface with a mycelial suspension of R-5.

1 Laboratory of Ecological Circulation, Mie University, Tsu 514-8507, Japan

2 Akatsuka Orchid Co. Ltd., Takanoo, Tsu 514-2221, Japan

3 College of Technology, Toyama Prefectural University, Kosugi-machi, Toyama 939-0398, Japan

4 Biotechnology Research Center, Toyama Prefectural University, Kosugi-machi, Toyama 939-0398, Japan

* Corresponding author (E-mail : kunoh@bio.mie-u.ac.jp) 


\section{MATERIALS AND METHODS}

Plants Flower buds were harvested from rhodo. dendron (a hybrid cultivar, Sakigake) and surfacesterilized in 1\% sodium hypochlorite for $5 \mathrm{~min}$, followed by washing in sterilized distilled water for a few minutes. They were further sterilized in $70 \%$ ethanol for $1 \mathrm{~min}$, then air-dried in a laminar flow chamber. They were placed on callus-inducing medium $\left[\mathrm{NH}_{4} \mathrm{CO}_{3}, 400 \mathrm{mg}\right.$; $\mathrm{KNO}_{3}, 480 \mathrm{mg} ; \mathrm{MgSO}_{4} \cdot 7 \mathrm{H}_{2} \mathrm{O}, 370 \mathrm{mg} ; \mathrm{FeSO}_{4} \cdot 7 \mathrm{H}_{2} \mathrm{O}$, $55.7 \mathrm{mg} ; \mathrm{Na}_{2} \cdot$ EDTA, $74.5 \mathrm{mg} ; \mathrm{CaCl}_{2} \cdot 2 \mathrm{H}_{2} \mathrm{O}, 440 \mathrm{mg}$; $\mathrm{MnSO}_{4} \cdot \mathrm{H}_{2} \mathrm{O}, 16.9 \mathrm{mg} ; \mathrm{ZnSO}_{4} \cdot 7 \mathrm{H}_{2} \mathrm{O}, 8.6 \mathrm{mg} ; \mathrm{H}_{3} \mathrm{BO}_{4}$, $6.2 \mathrm{mg} ; \mathrm{CoCl}_{2} \cdot 6 \mathrm{H}_{2} \mathrm{O}, 0.025 \mathrm{mg} ; \mathrm{CuSO}_{4} \cdot 5 \mathrm{H}_{2} \mathrm{O}, 0.025$ $\mathrm{mg} ; \mathrm{Na}_{2} \mathrm{MoO}_{4} \cdot 2 \mathrm{H}_{2} \mathrm{O}, 0.25 \mathrm{mg} ; \mathrm{NaH}_{2} \mathrm{PO}_{4} \cdot \mathrm{H}_{2} \mathrm{O}, 380 \mathrm{mg}$; myo-inositol, $100 \mathrm{mg}$; adenine sulfate $2 \mathrm{H}_{2} \mathrm{O}, 80 \mathrm{mg}$; thiamine hydrochloride, $0.4 \mathrm{mg} ; \mathrm{N}^{6}(2$-isopentenyl) adenine, $5.0 \mathrm{mg}$; sucrose, $30 \mathrm{~g}$; agar powder, $8.0 \mathrm{~g}$ in 1000 $\mathrm{ml}$ of distilled water; $\mathrm{pH} 4.5]$ in glass flasks in an incubator illuminated at $11.8 \mathrm{Wm}^{-2}$ per day for 1-2 months. Small pieces of the callus were transferred onto the multiplication medium $[4.0 \mathrm{mg}$ of indoleacetic acid and $15.0 \mathrm{mg}$ of $\mathrm{N}^{5}(2$-isopentenyl) adenine, instead of 5.0 $\mathrm{mg}$, were added to the callus-inducing medium]. They were incubated in growth chambers illuminated with lights of the same intensity (14 hr per day) at $25^{\circ} \mathrm{C}$. A number of young seedlings without roots emerged from calli within a month. These seedlings were aseptically separated and transferred to fresh multiplication medium and incubated in the same chamber for another month. The resultant seedlings were used for the following inoculation test. Ten to 12 clusters of seedlings were grown in a glass flask.

Preparation of mycelial suspension of Streptomyces sp. R-5 and treatment of multiplication medium A spore suspension of Streptomyces sp. R-5 in 20\% glycerol supplemented with DMSO was transferred from the stock culture to IMA.2 liquid medium ${ }^{18)}$ in a glass flask and incubated on a rotary shaker at $200 \mathrm{rpm}$ at $30^{\circ} \mathrm{C}$ for $12 \mathrm{hr}$. A mycelial suspension $\left(3-4 \times 10^{6} \mathrm{cfu} / \mathrm{ml}\right)$ was prepared from this culture. One $\mathrm{ml}$ of the mycelial suspension was dropped and spread on the surface of the multiplication medium in glass flasks with rhododendron seedlings that were growing as described. In untreated controls, $1 \mathrm{ml}$ of IMA-2 liquid medium was spread on the medium surface. The seedlings, treated and untreated with R-5, were incubated for an additional 10 days before inoculation of Pestalotiopsis sydowiana.

Inoculation of rhododendron seedlings with Pestalotiopsis sydowiana and evaluation of disease severity Pestalotiopsis sydowiana (Bresadola) Sutton, a causal pathogen of rhododendron Pestalotia disease (provided by the National Institute of Agrobiological
Resources, stock No. 305755), was cultured on potato dextrose agar (PDA) at $25^{\circ} \mathrm{C}$ for 5 days. Mycelial disks (4. $\mathrm{mm}$ diameter) were then transferred onto the 4th upper leaf of the rhododendron seedlings with R-5 in glass flasks as described, followed by incubation for 14 days at $25^{\circ} \mathrm{C}$ and $11.8 \mathrm{Wm}^{-2}$ for $12 \mathrm{hr}$ per day. In controls untreated with R-5, similar mycelial disks were placed on the 4th upper leaf.

All seedlings were taken out of the flasks 7 or 14 days after inoculation with $P$. sydowiana, and growth of R-5 and $P$. sydowiana on leaves and stems was carefully observed with a dissecting microscope. The cluster of seedlings was separated into individuals with a forceps. A total of 66 and 24 seedlings, pretreated with R-5 and then inoculated with $P$. sydowiana, was observed 1 and 2 weeks after inoculation, respectively. For controls untreated with R-5, 28 seedlings were observed at 1 and 2 weeks.

Symptoms on the seedlings were observed by naked eye and categorized as follows : i) no change on inoculated 4th leaves, ii) brownish symptom on inoculated leaves, iii) brownish symptom on 3 rd-5th leaves, iv) browning of entire seedling. The incidence for each category was expressed as a percentage of the number of seedlings in the category per total number of observed seedlings (Table 1). The growth of aerial and substrate mycelia of $P$, sydowiana on seedlings were examined with a dissecting microscope.

Reisolation of R-5 from rhododendron seedlings Seedlings treated with R-5 were taken from one flask on designated days until the 14th day after the onset of treatment. Each seedling was cut into pieces at every two nodes, and the respective pieces with leaves were surface-sterilized as follows : rinsed in $0.1 \%$ Tween 20 for a few seconds, then in $1 \%$ sodium hypochlorite for 5 min, followed by washing in sterilized distilled water for a few minutes. They were further surface-sterilized in $70 \%$ ethanol for $1 \mathrm{~min}$ and air-dried in a laminar flow chamber. Each piece was placed on IMA-2 agar medium, then incubated at $30^{\circ} \mathrm{C}$ for about 1 month. To avoid transferring R-5 from one piece to another, each piece was sterilized in a separate Eppendorf tube.

Fluorescence and scanning electron microscopy (SEM) Seedlings in flasks of multiplication medium treated with R-5 were removed 10 days after the onset of treatment. Small pieces of their leaves were surfacesterilized as described and incubated on IMA-2 medium for 7 days. Specimens were fixed in $3 \%$ formaldehyde $(\mathrm{pH}$ 7.4) for $3 \mathrm{hr}$, followed by dehydration in an ethanol series (30-100\%) and embedment in resin (Historesin Plus, Leica Inst., Heidelberg, Germany). Blocks of this resin were cut into $4-8 \mu \mathrm{m}$ sections with glass knives. The sections attached to glass slides were stained with $0.01 \%$ 
acridine orange ${ }^{5)}$ and observed under UV irradiation with a fluorescence microscope. Other stem and leaf pieces were fixed in $5 \%$ glutaraldehyde containing $0.2 \%$ tannic acid for $3 \mathrm{hr}$, then in $5 \%$ glutaraldehyde containing $2 \%$ tannic acid for $3 \mathrm{hr}$. After washing with deionized water several times, they were fixed in $1 \% \mathrm{OsO}_{4}$ for $3 \mathrm{hr}$, followed by dehydration in an ethanol series (30-100\%). The specimens were rinsed in iso-amyl acetate and dried with a critical point dryer. They were attached onto specimen stubs and observed with a scanning electron microscope (Hitachi Co., S-4000) after gold coating.

\section{RESULTS}

When R-5 was placed on the multiplication medium in a glass flask with rhododendron seedlings, mycelia of R-5 grew and sporulated to form white, powdery colonies on the medium surface within 2-3 days. Their growth did not cause any adverse effects on the seedlings.

When the 4th leaves of rhododendron seedlings in the multiplication medium untreated with $R-5$ were inoculat- ed with Pestalotiopsis sydowiana, a whitish aerial and substrate mycelia of $P$. sydowiana actively grew on the inoculated leaves and neighboring leaves by 3 days after inoculation. By 7 days, the 3rd and 5th leaves turned brownish (Plate I-A, left). All leaves and stems of seedlings in untreated controls turned brownish by 14 days after inoculation and the entire seedlings wilted (Plate I-B, left). However, when the medium surface was treated with R-5, substrate mycelia of $P$. sydowiana stayed on the 4th leaves; their growth to the upper or lower leaves was not visible by the naked eye (Plate I-A, right). Consequently, all leaves aside from the inoculated leaves remained green for 14 days (Plate I-B, right). Another interesting point was that stems of the seedlings turned reddish from the base to the top by the 4 th day after the onset of R-5 treatment. Because R-5 untreated control seedlings, with or without inoculation of $P$. sydowiana, never turned red, the color change is attributable to the treatment of the medium surface with R-5.

In R-5 untreated controls, only the inoculated leaves turned brownish in $43 \%$ of seedlings (Table 1 ). The upper

Table 1. Incidence of Pestalotia disease caused by inoculation with $P$. sydowiana in rhododendron seedlings pre-treated and untreated with Streptomyces sp. R.5

\begin{tabular}{|c|c|c|c|}
\hline \multirow{2}{*}{$\mathrm{R}-5$ treatment } & \multirow{2}{*}{ Symptom } & \multicolumn{2}{|c|}{ Incidence after inoculation } \\
\hline & & 7 days & 14 days \\
\hline \multirow[t]{4}{*}{ Untreated } & No symptoms & $7 \%$ & $0 \%$ \\
\hline & Only inoculated leaf brownish & $43 \%$ & $10 \%$ \\
\hline & Entire stem, leaves above and below inoculated leaf brownish & $50 \%$ & $36 \%$ \\
\hline & Entire seedling killed & $0 \%$ & $54 \%$ \\
\hline \multirow[t]{4}{*}{ Pretreated } & No symptoms & $6 \%$ & $8 \%$ \\
\hline & Only inoculated leaf brownish & $94 \%$ & $92 \%$ \\
\hline & Entire stem, leaves above and below inoculated leaf brownish & $0 \%$ & $0 \%$ \\
\hline & Entire seedling killed & $0 \%$ & $0 \%$ \\
\hline
\end{tabular}

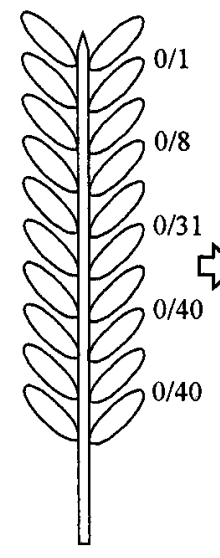

0-3days

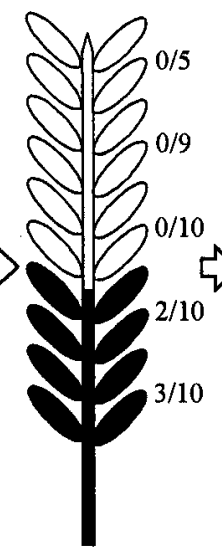

4days

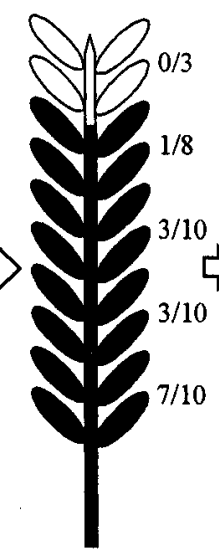

5 days
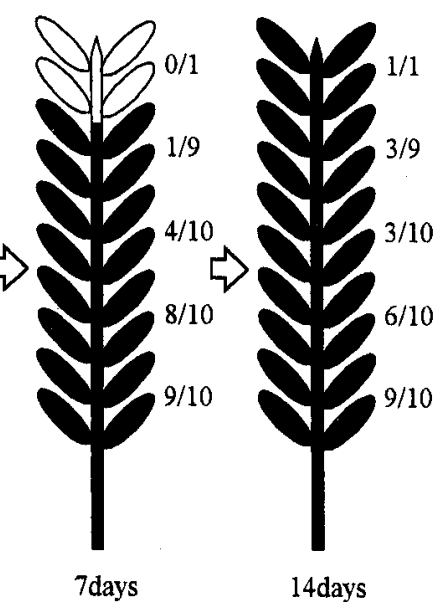

Fig. 1. Nodes of rhododendron seedlings from which R-5 was reisolated. Black leaves and stems indicate where R-5 was reisolated. $x / y$ : No. of seedlings from which R-5 was isolated/Total no. of seedlings 
and lower leaves browned in $50 \%$ seedlings by 7 days after inoculation. By 14 days, $54 \%$ of seedlings were completely browned and wilted. These numerical data, which support the previously described observations, show that $P$. sydowiana quickly spreads from the in oculated leaves to the entire seedlings within 14 days if the seedlings were not pre-treated with R-5. In contrast, in $92-94 \%$ of R-5-treated seedlings only the inoculated leaves turned brownish within 14 days. Dissecting microscopy revealed that in R-5 pretreated seedlings only a few aerial mycelia and none of the substrate mycelia grew from the inoculated disk on the 4th leaves to neighboring leaves and stems. In untreated controls, however, aerial and substrate mycelia grew abundantly from the inoculation site to upper and lower stems and leaves. This observation suggests that contact of aerial mycelia probably did not cause browning of plant tissues, although a more detailed observation of the contact side is required.

As illustrated in Fig. 1, R-5 was reisolated from the base and the 1st and 2nd basal pieces of seedlings by the 4th day after treatment and from the 3rd and 4th pieces by the 5 th and 7 th day. Although $\mathrm{R} .5$ was reisolated from entire seedlings by the 14th day, the frequency of isolation and location of reisolation were not consistent during the sampling period.

Figure 2 illustrates growth of R-5 on rhododendron
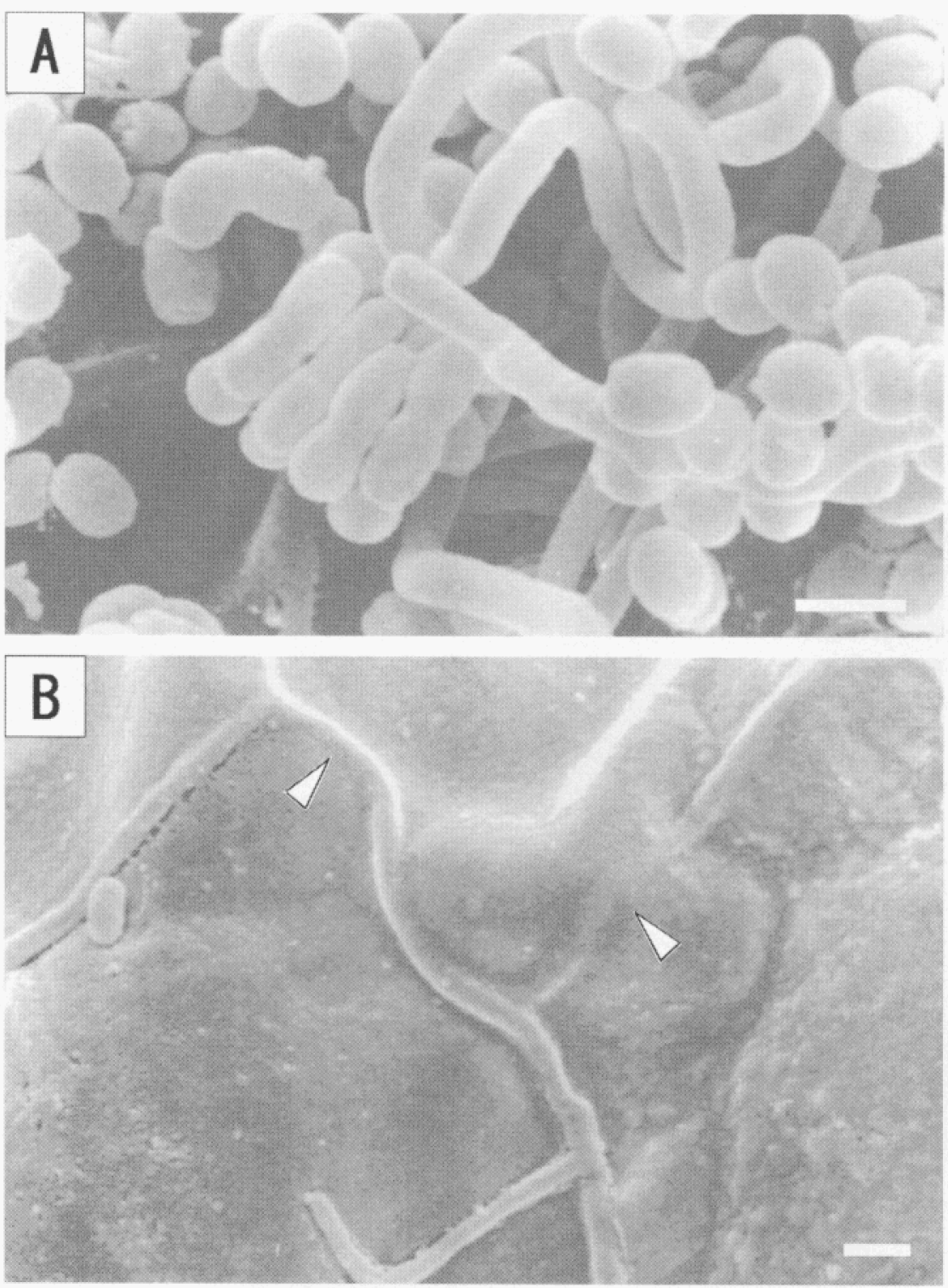

Fig. 2. Scanning electron micrographs showing hyphae of R-5 on rhododendron leaf surfaces. (A) Spores of R-5. (B) Growth of R-5 hyphae. Arrowheads point to R-5 hyphae beneath cuticle (scale $=1 \mu \mathrm{m}$ ). 
leaves. Aerial hyphae were $0.4-0.6 \mu \mathrm{m}$ wide. Ellipsoidal spores $(0.4-0.6 \times 0.3-0.4 \mu \mathrm{m})$ were smooth and in spiral chains (Fig. 2A). Substrate mycelia grew on the surface of the cuticle as well as beneath it in places (Fig. 2B). Because specimens were fixed chemically and dehydrated with ethanol, profiles of epicuticular wax had changed during specimen preparation. How and where R-5 penetrated the epidermal cell walls beneath the cuticle could not be determined by SEM.

In sections of the seedling leaves, mycelia of R-5 were positively stained by acridine orange and located outside and inside leaves (arrows in Plate I-C). Mycelia reproduced abundantly in leaf tissues, pushed the epidermises outward, then grew out of epidermal cracks (Plate I-C). Within the leaves, they were especially in mesophyll cells and intercellular spaces.

These SEM and fluorescence microscopic observations suggest that i) mycelia of R.5 might expand onto the cuticle surface of seedlings from the medium surface and grow upward along the stems, ii) R-5 penetrates into leaf and stem tissues, and/or iii) spores that formed either on the medium or plant surfaces could be disseminated from the base to the upper part of plants by air movement within the flask. To examine this third possibility, a long piece of glass slide painted with glycerin was hung parallel to seedlings in an R-5-treated flask and incubated for a week. Because no growth of R-5 was detected on the glass slide, we concluded that R-5 grew upwards on and/ or in the seedlings and that spores did not spread through the within the closed flasks. Before this experiment, we confirmed that R-5 could actively grow on a glycerincovered glass slide.

\section{DISCUSSION}

The endophytic presence of Streptomyces spp. may have important roles in plant development and health because they can affect plant growth either by nutrient assumption or by secondary metabolite production ${ }^{16)}$. Matsukuma et al..$^{6)}$ and Okazaki et al. ${ }^{12)}$ reported that a variety of actinomycetes inhabit a wide range of plants as either symbionts or parasites. Sato et $a{ }^{17}{ }^{17}$ attempted to isolate endophytic actinomycetes from 27 species of 20 genera in $\mathbf{1 5}$ families of higher plants and found that at least one species of actinomycetes could be isolated from all test plants. Thus, endophytic actinomycetes are distributed commonly in a wide range of higher plants. In this study we demonstrated that pretreatment of the medium surface with R-5, an endophytic actinomycete, rendered tissue-cultured seedlings of rhododendron to be resistant to Pestalotiopsis sydowiana. The present method for inducing disease resistance in tissue-cultured seedlings is quite unique when compared to earlier reports on biocontrol with the soil application of agents $^{3,13,14,24,25)}$. As discussed by Rukayadi et $a l^{15)}$, the respective microbes may respond differently to changing environmental conditions and may lose their efficacy in fields. This flask method is advantageous because disease resistance of the seedlings is induced in a controlled environment without any adverse environmental influence on R-5.

Mulya et $a l^{7)}$ reported suppressive effects against bacterial wilt disease of tomato after root dipping in Pseudomonas fluorescens PfG32 and suggested that production of antibiotic substances and siderophores within tomato tissues might be associated with this suppression. Because R-5 had a broad antimicrobial spectrum from bacteria to fungi ${ }^{18}$, this isolate may produce a variety of these materials. Furthermore, we detected actinomycin and polyene antifungal antibiotics in IMA-2 liquid medium where R-5 had been cultured. When the multiplica. tion medium in which rhododendron seedlings were growing was treated with R-5, we also detected actinomycin in extracts of both the medium and the seedlings ${ }^{19)}$. Thus, two possibilities must be considered : i) antibiotics produced in the medium by R-5 might be absorbed by the seedlings, and ii) R-5 growing on and/or in the seedlings might produce these antibiotics within the tissues. Because $P$. sydowiana was sensitive to more than $10 \mathrm{ppm}$ of actinomycin $D$ in the solid medium, the presence of this antibiotic either in or on the seedlings may be involved in the putative resistance of the seedlings.

Because of the red color that developed on the rhododendron stems after treatment with R-5, anthocyanin pigments may be related to an induction of resistance similar to that in maize and $\operatorname{corn}^{1,4,20)}$. Hammerschmidt and Nicholson ${ }^{4)}$ reported that in many corn cultivars when the resistance response was terminated, anthocyanin pigments were synthesized in a zone immediately surrounding lesions. Snyder and Nicholson ${ }^{20)}$ identified these pigments as apigeninine and luteonidinine, which are synthesized through the phenylpropanoid pathway, and defined them as phytoalexins of maize plants. Based on these earlier reports, an accumulation of anthocyanin pigments in rhododendron might also be involved in a systemic acquired resistance. This attractive theme is now under investigation.

As reported in a previous paper ${ }^{18)}$, about 1 month was required for the endophytic actinomycetes to appear on epidermises of surface-sterilized rhododendron that had been harvested from fields, suggesting that in nature R-5 probably survives endophytically. Nevertheless, only 3-4 days were required for reisolation of R-5 from segments of seedlings that had basal parts treated with an R-5 suspension. These results led us to assume that i) surface sterilization might not be enough to kill all the surface- 
colonized $R+5$, and ii) $R-5$, which inhabits epidermal tissues, may grow outward within a few days after surface sterilization. If the second assumption is correct, the growth pattern of R-5 in the flasks might be different from that in nature. Thus, the mode of R-5 colonization within the flask environment are now being examined cytologically.

Interestingly, mycelia of R-5 grew underneath the surface of cuticle (Fig. 2B). Such a growth pattern is similar to that of Zygophiala jamaicensis on berry and fruit surfaces of various plants ${ }^{9,10)}$, Pestalotia malicola on fruits of Chinese quince ${ }^{21}$, and P. subcuticularis on leaves of Hymenaea courbaril ${ }^{2}$. Zygophiala jamaicensis is also an epicuticular habitant that grows and sporulates only on the berry or fruit surface without penetrating internal tissues. Sugui et al. ${ }^{21)}$ assumed that the ability of $P$. malicola to grow in association with the cuticle probably represented production of cutinase(s) and/or non-specific esterase(s). They revealed by enzymatic assay that the fungus produced an enzyme(s) with activities characteristic of a cutinase and a non-specific esterase when cultured on cucumber cutin as the sole carbon source. From their evidence, we propose an additional theme: R-5 can produce similar enzymes.

Nasu and Kunoh ${ }^{11}$ reported that mycelia of $Z$. jamaicensis could develop and form conidia and sclerotium.like structures on the isolated waxy bloom and a commercially available polyhydrocarbon on glass slides. They concluded that this fungus is an ectoparasite that can utilize solely the bloom for its survival. Our preliminary experiment showed that R-5 also grew and sporulated on waxes isolated from rhododendron leaves (data not shown), suggesting that R-5 has an ectoparasitic capability. However, because R.5 grows in internal tissues of leaves (Plate I-C), R-5 somehow penetrates into the internal tissues of rhododendron and survives there as an endosymbiont or parasite. The mode of infection of these tissues by R-5 is now being investigated.

As discussed here, many questions remain to be solved in this technique to induce disease resistance in tissuecultured seedlings of rhododendron. Nevertheless, the endophytic symbiosis of actinomycetes may play an important role in protecting their host plants from diseases in nature.

\section{ACKNOWLEDGMENTS}

Contribution No. 8 from Laboratory of Ecological Circulation, Faculty of Bioresources, Mie University. We thank Dr. Beth E. Hazen for correction of the English and valuable suggestions. Work was partially supported by Grants-in-Aid for Scientific Research on Priority Areas (A) (2) No. 393 and for Scientific Research (A) (No. 10306004) from the Ministry of Education, Culture, Sports, Science and Technology of Japan to Hitoshi Kunoh.

\section{LITERATURE CITED}

1. Bergstrom, G.C. and Nicholson, R.L. (1999). The biology of corn anthracnose : Knowledge to exploit for improved management. Plant Dis. 83: 596-608.

2. Fail, G.L. and Langenheim, J.H. (1990). Infection processes of Pestalotia subcuticularis on leaves of Hymenaea courbaril. Phytopathology $80: 1259-1265$.

3. Green, H., Larsen, J., Olsson, P.A., Jensen, D.F. and Jackson, I. (1999). Suppression of the biocontrol agent Trichoderma harzianum by mycelium of the arbuscular mycorrhizal fungus Glomus intraradices in root-free soil. Appl. Environ. Microbiol. 65 : 1428-1434.

4. Hammerschmidt, R. and Nicholson, R.L. (1977). Resistance of maize to anthracnose : Changes in host phenols and pigments. Phytopathology $67: 247-250$.

5. Kunoh, H., Takeshima, H. and Ishizaki, H. (1981). Studies of the powdery mildew fungus, Leveillula taurica, on green pepper. IV. The acridine-orange staining of haustoria and related structures. Trans. Mycol. Soc. Jpn. $22: 353-356$.

6. Matsukuma, S., Okuda, T. and Watanabe, J. (1994). Isolation of Actinomycetes from pine litter layers. Actinomycetology $8: 57-65$.

7. Mulya, K., Watanabe, M., Goto, M., Takikawa, Y. and Tsuyumu, S. (1996). Suppression of bacterial wilt disease of tomato by root-dipping with Pseudomonas fluorescens PfG32-The role of antibiotic substances and siderophore production. Am. Phytopathol. Soc. Jpn. 62 : 134-140.

8. Narisawa, K., Tokumasu, S. and Hashiba, T. (1998). Suppression of clubroot formation in Chinese cabbage by the root endophytic fungus, Heteroconium chaetospira. Plant Pathol. $47:$ 206-210.

9. Nasu, H. and Kunoh, H. (1986). A unique sclerotiumlike structure produced by Zygophiala jamaicensis on grape berries. Trans. Mycol. Soc. Jpn. $27: 225-233$.

10. Nasu, H. and Kunoh, H. (1987). Scanning electron microscopy of flyspeck of apple, pear, Japanese persimmon, plum, Chinese quince and pawpaw. Plant Dis. 71 : 361-364.

11. Nasu, H. and Kunoh, H. (1993). The pathological anatomy of Zygophiala jamaicensis on fruit surfaces. In Handbook of Cytology, Histology, and Histochemistry of Fruit Tree Diseases (Biggs, A.L., ed.). pp. 137-155, CRC Press, Boca Raton, U.S.A.

12. Okazaki, T., Takahashi, K., Kizuka, M. and Enokita, R. (1995). Studies on Actinomycetes isolated from plant leaves. Annu. Rep. Sankyo Res. Lab. 47 : 97-106.

13. Oshiman, K., Ohta, T., Kobori, H. and Kunoh, H. (1998). Studies on the turfgrass snow mold caused by Typhula ishikariensis on bentgrass with an antagonistic bacterium. J. Jpn. Soc. Turfgrass $26: 95-112$. 
14. Rodriguez, F. and Pfender, W.F. (1997). Antibiosis and antagonism of Sclerotinia homoeocarpa and Drechslera poae by Pseudomonas fluorescens Pf-5 in vitro and in planta. Phytopathology $87: 614-621$.

15. Rukayadi, Y., Suwanto, A., Tjahjono, B. and Harling, R. (2000). Survival and epiphytic fitness of a nonpathogenic mutant of Xanthomonas campestris pv. glycines. Appl. Environ. Microbiol. 66 : 1183-1189.

16. Sardi, P., Saracchi, M., Ouaroni, S., Petrolini, B., Borgonovoli, G.E. and Merli, S. (1992). Isolation of endophytic Streptomyces from surface-sterilized roots: Appl. Environ. Microbiol. 58 : 2691-2693.

17. Sato, Y., Shibata, Y., Yoshida, R., Kunoh, H., Saito, N., Igarashi, Y, Onaka, H. and Furumai, T. (2000). Studies on endophytic Actinomycetes. (1). Isolation of Actinomycetes from plants and bioactivity of their secondary metabolites. p. 300. In Abstr., The 1st Asian Conference on Plant Pathology, Beijing, China.

18. Shimizu, M., Nakagawa, Y., Sato, Y., Furumai, T., Igarashi, Y., Onaka, H., Yoshida, R. and Kunoh, H. (2000). Studies on endophytic actinomycetes (1). Streptomyces sp. isolated from rhododendron and its antifungal activity. J. Gen. Plant Pathol. 66 : 360-366.

19. Shimizu, M., Furumai, T., Igarashi, Y., Onaka, H., Nishimura, T., Yoshida, R. and Kunoh; H. (2001). Association of induced disease resistance of rhododendron seedlings with inoculation of Streptomyces sp. R-5 and treatment with actinomycin $\mathrm{D}$ and amphotericin $\mathrm{B}$ to the tissue-culture medium. J. Antibiot. 54:501-505.

20. Snyder, B.A. and Nicholson, R.L. (1990). Synthesis of phytoalexins in sorghum as a site specific response to fungal ingress. Science 248 : 1637-1639.

21. Sugui, J.A., Pascholati, S.F., Kunoh, H., Howard, R.J. and Nicholson, R.L. (1998). Association of Pestalotia malicola with the plant cuticle: Visualization of the pathogen and detection of cutinase and non-specific esterase. Physiol. Mol. Plant Pathol. 52 : 213-221.

22. van Wees, S.C. M., Luijendijk, M., Smoorenburg, I., van Loon, L.C. and Pieterse, C.M.J. (1999). Rhizobacteriamediated induced systemic resistance (ISR) in Arabidopsis is not associated with a direct effect on expression of known defense-related genes but stimulates the expression of the jasmonate-inducing gene Atusp upon challenge. Plant Mol. Biol. 41 : 537-549.

23. Varma, A., Verma, S., Suda, Sahay, N., Bütehorn, B. and Franken, P. (1999). Piriformospora indica, a cultivable plant-growth-promoting root endophyte. Appl. Environ. Microbiol. 65 : 2741-2744.

24. Zhang, Z. and Yuen, G. Y. (1999). Biological control of Bipolaris sorokiniana on tall fescue by Stenotrophomonas maltophilia strain C3. Phytopathology 89 : 817-822.

25. Zhou, T. and Boland, G. J. (1998). Suppression of dollar spot by hypovirulent isolates of Sclerotinia homoeocarpa. Phytopathology $88: 788-794$.

\section{Explanation of plate}

\section{Plate I}

A,B. Symptom development caused by Pestalotiopsis sydowiana on tissue-cultured seedlings of rhododendron pretreated and untreated with R-5 (A, 7 days after inoculation with $P$. sydowiana; B, 14 days). A mycelial disk of $P$. sydowiana was placed on the upper 4 th leaf (arrowheads) 10 days after pretreatment with R-5. Seedlings, R-5 untreated and $P$. sydowiana inoculated (left). Seedlings, R-5 treated and $P$. sydowiana inoculated (right). Note that stems and leaves of the R-5 treated seedlings turned reddish.

C. Acridine-orange staining of leaf section pretreated with R-5 and incubated on IMA-2 agar medium for 4 days. Arrows point to mycelia of R-5. 


\section{Plate I}
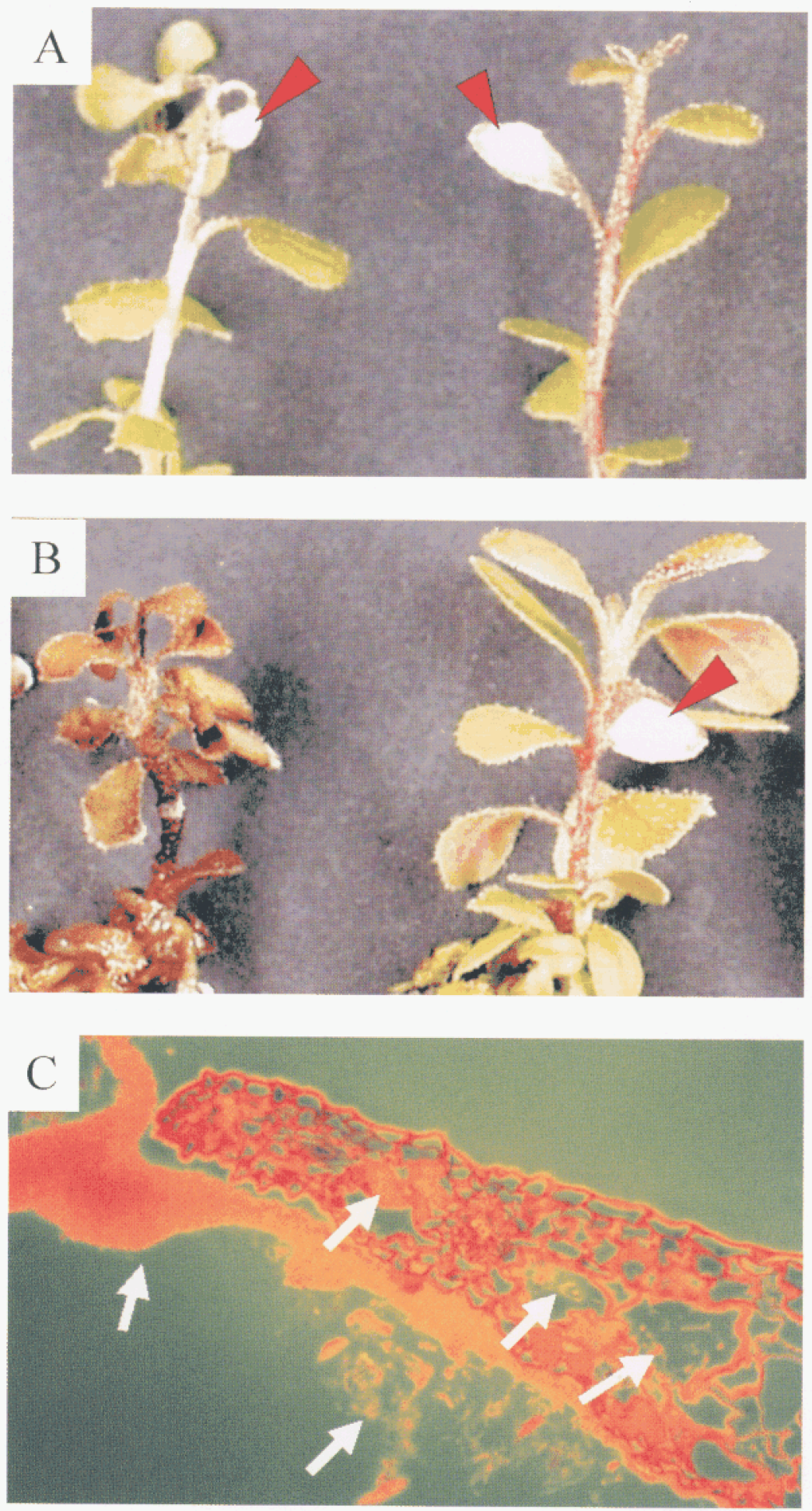